\title{
Warming patterns in regional climate change projections over the Iberian Peninsula
}

ARTICLE in METEOROLOGISCHE ZEITSCHRIFT · JUNE 2010

Impact Factor: 1.19 · DOI: 10.1127/0941-2948/2010/0351

6 AUTHORS, INCLUDING:

Juan José Gómez-Navarro

Universität Bern

36 PUBLICATIONS 302 CITATIONS

SEE PROFILE

Pedro Jimenez-Guerrero

University of Murcia

150 PUBLICATIONS $\quad \mathbf{1 , 7 1 7}$ CITATIONS

SEE PROFILE

\section{J.P. Montávez}

University of Murcia

115 PUBLICATIONS 961 CITATIONS

SEE PROFILE

J. Fidel González Rouco

Complutense University of Madrid

186 PUBLICATIONS $\quad 3,670$ CITATIONS

SEE PROFILE 


\title{
Warming patterns in regional climate change projections over the Iberian Peninsula
}

\author{
J.J. Gómez-NAVArro ${ }^{1}$, J.P. Montávez ${ }^{1 *}$, P. Jimenez-Guerrero ${ }^{1}$, S. Jerez ${ }^{1}$, J.A. \\ GARCÍA-VALERO ${ }^{1,2}$ and J. F. GonZÁleZ-RouCO ${ }^{3}$ \\ ${ }^{1}$ Departamento de Física, Universidad de Murcia, Spain \\ ${ }^{2}$ Agencia Estatal de Meteorología (AEMET), Delegación Territorial en Murcia, Spain \\ ${ }^{3}$ Departamento de Astrofísica y CC. de la Atmósfera, Universidad Complutense, Madrid, Spain \\ (Manuscript received October 31, 2009; in revised form March 10, 2010; accepted March 11, 2010)
}

\begin{abstract}
A set of four regional climate change projections over the Iberian Peninsula has been performed. Simulations were driven by two General Circulation Models (consisting of two versions of the same atmospheric model coupled to two different ocean models) under two different SRES scenario. The XXI century has been simulated following a full-transient approach with a climate version of the mesoscale model MM5. An Empirical Orthogonal Function analysis (EOF) is applied to the monthly mean series of daily maximum and minimum 2-metre temperature to extract the warming signal. The first EOF is able to capture the spatial structure of the warming. The obtained warming patterns are fairly dependent on the month, but hardly change with the tested scenarios and GCM versions. Their shapes are related to geographical parameters, such as distance to the sea and orography. The main differences among simulations mostly concern the temporal evolution of the warming. The temperature trend is stronger for maximum temperatures and depends on the scenario and the driving GCM. This asymmetry, as well as the different warming rates in summer and winter, leads to a continentalization of the climate over the IP.

Zusammenfassung

Vier regionale Projektionen des Klimawandels im Bereich der Iberischen Halbinsel werden vorgestellt. Die zu Grunde liegenden numerischen Simulationen wurden durch die Ergebnisse aus je zwei unterschiedlichen globalen Zirkulationsmodellen (GCM) angetrieben, welche jeweils das identische Atmosphärenmodul mit unterschiedlichen Ozeanmodulen kombinieren. Dabei wurden für zwei SRES-Szenarios behandelt. Das XXI. Jahrhundert wurde zeitabhängig mit einer klimatauglichen Version des ursprünglich mesoskaligen MM5Modells simuliert. Die resultierenden Zeitreihen der täglichen Maximaltemperatur und Minimaltemperatur in 2 m Höhe wurden mit der Methode der empirischen orthogonalen Funktionen (EOF) analysiert, um das Signal der Erwärmung zu extrahieren. Die erste EOF gibt die räumliche Struktur des Erwärmungsmusters wieder. Diese Muster sind deutlich monatsabhängig, unterscheiden sich jedoch kaum für die beiden Szenarios und die Versionen des antreibenden GCM. Ihre Eigenschaften hängen mit geographischen Parametern zusammen, wie zum Beispiel dem Abstand zur Küste und der Orographie. Die wichtigsten Unterschiede zwischen den Simulationen betreffen die zeitliche Entwicklung der Erwärmung. Dieser Trend ist ausgeprägter für die Maximaltemperaturen, und hängt von den Szenarios und den antreibenden GCM ab. Die zunehmenden täglichen Differenzen in Kombination mit den unterschiedlichen Erwärmungsraten in Sommer und Winter bedeuten eine Kontinentalisierung des Klimas der Iberischen Halbinsel.
\end{abstract}

\section{Introduction}

Climate change is one of the problems of most concern, as pointed out by the last report of the IPCC (IPCC, 2007). More specifically, the Iberian Peninsula (IP), as part of the Mediterranean Region, has been identified as one of the Hot-Spots of climate change (GIORGI, 2006; DiFFENBAUGH et al., 2007).

Projections of future climate can be performed by General Circulation Models (GCMs), whose external forcings are based on the IPCC Special Report on Emission Scenarios (SRES) (HOUGHTON et al., 2001). These models reproduce large-scale circulation, but their performance in reproducing regional climate details is poor due to their coarse resolution (RIND et al., 1990; VON

\footnotetext{
*Corresponding author: J.P. Montávez, Departamento de Física, Universidad de Murcia, Spain, e-mail: montavez@um.es
}

STORCH, 1995). For this reason, downscaling techniques are necessary in order to capture the fine scale structure of climate change, especially in areas with complex topography and great climatic diversity such as the IP (FONT-TULLOT, 2000).

Several downscaling techniques exist, such as statistical downscaling (WILBY et al., 1998; TRIGO and PALUTIKOF, 2001; XOPLAKI et al., 2004), in which statistical/empirical models link the large-scale fields with local or regional variables, and dynamic downscaling, performed by means of Regional Climate Models (RCMs) nested to GCMs. The latter allows climate change projections at higher spatial resolution for a limited-area domain (GIORGI et al., 2004a,b; RAISANEN et al., 2004; SOLMAN et al., 2008; NunEZ et al., 2009, and many others). The higher resolution and more complete physical representation reduce some driving GCM biases in 
the present climate and thus enhance the credibility of future climate change projections (LIANG et al., 2008).

Climate change projections are nevertheless affected by three sources of uncertainty: emission scenario uncertainty, internal variability and model uncertainty. The first is caused mostly by external-to-climate factors such as the evolution of economy and technology. The second is inherent to the climate system, and its importance decreases at multidecadal time scales (HAWKINS and SUTTON, 2009). The last source, model uncertainty, is due to the misrepresentation in the models of some important physical processes. In regional climate change projections, model uncertainty arises from uncertainties in the GCM driving the simulation and from the RCM itself (GIORGI, 2005). These uncertainties can be evaluated through the spread in ensembles of equivalent simulations (DÉQUE et al., 2007; JACOB et al., 2007).

In the case of the European Continent, several studies have focused on assessing the accuracy on different RCMs in reproducing the climatology observed for a control period (usually 1960-1990) (DÉQUE et al., 2005; JACOB et al., 2007), as well as on evaluating the spread among climate change projections (DÉQUE et al., 2007). Many of these works lie within the context of the PRUDENCE and ENSEMBLES projects (5Th and 6Th EU Framework Programme, respectively).

The most frequent approach adopted for the evaluation of projected warming is the future-minus-present method, which is based on the assumption that biases in simulated present-day and future climates will tend to cancel each other, and thus their difference captures the climate change signal. Although supported by intercomparisons between climate models (KITTEL et al., 1998), this approach is very sensitive to the chosen periods due to the inherent internal variability of the climate models, especially at regional scales (RAISANEN, 2001). Although computationally expensive, full transient simulations minimise the internal variability uncertainty due to the longer time series obtained.

The aim of this work is to check whether the projected warming over the IP is dependent, and to what extent, on the SRES scenario and the GCM version driving the regional simulation. For this purpose a set of four full transient regional climate change projections for the XXI century has been carried out using a climate version of the mesoscale model MM5 (FERNANDEZ et al., 2007; MontáveZ et al., 2006, 2008) driven by two versions of the atmospheric model ECHAM coupled to two different ocean models, and two SRES scenarios. The physical configuration and domain setup is the same in all the experiments, as a study of the uncertainty linked to the RCM itself is not the aim of this work. In order to capture the warming signal, an Empirical Orthogonal Functions analysis is applied, following an approach similar to ZORITA et al. (2005). This methodology, not previously employed in RCM studies, tries to overcome the problem linked to the internal variability of RCMs.
The study focuses on the evolution of monthly mean series of daily maximum and minimum 2-metre temperatures separately.

\section{Methodology}

\subsection{Experiment description}

The regional climate model used for the present study is a climate version of the Fifth-generation PennsylvaniaState University - National Center for Atmospheric Research Mesoscale Model (DUDHIA, 1993; GRELL et al., 1994; Montávez et al., 2006). Some other versions have been widely used in other regional climate change projections (BoO et al., 2004; NUNEZ et al., 2009)

Figure 1 depicts the two two-way nested domains with a resolution of $90 \mathrm{~km}$ and $30 \mathrm{~km}$, respectively, employed in all the simulations. The mother domain covers Europe and the Mediterranean Sea, which has been shown to strongly influence the climate of the eastern part of the Iberian Peninsula (FonT-Tullot, 2000). The second domain covers the IP with higher resolution. 24 sigma levels are considered in the vertical, with the top at 100 $\mathrm{hPa}$. A blending area of five grid points, shown in grey squares in Figure 1, is excluded from the analysis hereafter.

The same physical configuration is used in all simulations. It has been chosen in order to minimise the computational cost, since none of the tested configurations provides the best performance for all kinds of synoptic events and regions (FERNANDEZ et al., 2007). The physical options implemented are: Grell cumulus parametrisation (GRELL, 1993), Simple Ice for microphysics (DUDHIA, 1989), RRTM radiation scheme (MLAWER et al., 1997) and MRF for planetary boundary layer (HONG and PAN, 1996). The Noah Land-Surface model (CHEN and DUdHIA, 2001a,b) has been used, as it simulates more accurately the climate in dry areas, especially in summer over the southern part of the IP (MONTÁ VEZ et al., 2008)

Four experiments have been carried out using two versions of the atmospheric model ECHAM coupled to two different ocean models (hereafter denominated ECHO-G and ECHAM5, respectively) as boundary conditions under two different SRES scenarios. Table 1 summarises the four experiments, with the GCM employed, the scenario and the period covered. It should be noted that the only difference between the chosen scenarios is the Green House Gas (GHG) concentrations.

The ECHO-G model driving the EGA2 and EGB2 experiments consists of the spectral atmospheric model ECHAM4 coupled to the ocean model HOPE-G (LEGUTKE and Voss, 1999). The model ECHAM4 is used with a horizontal resolution $\mathrm{T} 30\left(\sim 3.75^{\circ} \times 3.75^{\circ}\right)$. The horizontal resolution of the ocean model is approximately $2.8^{\circ} \times 2.8^{\circ}$, with a grid refinement in the tropical regions. A flux adjustment constant in time was applied 


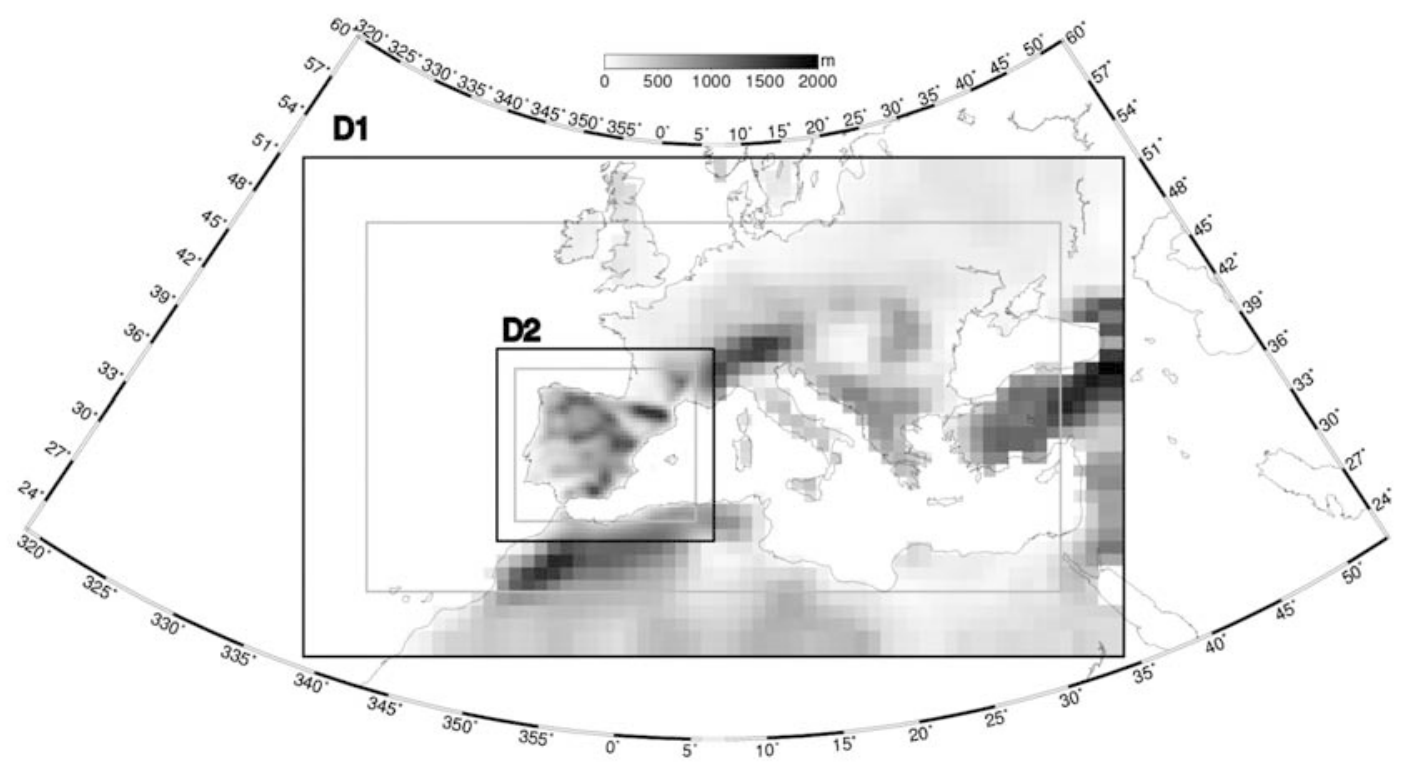

Figure 1: Nested domains D1 and D2 with $90 \mathrm{~km}$ and $30 \mathrm{~km}$ grid sizes, respectively, used in the simulations. The grey scale represents the orography seen by the model and grey rectangles indicate the blending area used for both domains.

Table 1: Experiment alias, GCM used, SRES scenario and time period covered by the four experiments.

\begin{tabular}{cccc}
\hline Experiment & GCM & Scenario & Period \\
\hline EGA2 & ECHO-G & A2 & $1991-2099$ \\
EGB2 & ECHO-G & B2 & $1991-2099$ \\
E5A2 & ECHAM5 & A2 & $2002-2099$ \\
E5B1 & ECHAM5 & B1 & $2002-2099$ \\
\hline
\end{tabular}

to avoid climate drift. A more detailed description of the model can be found in (ZORITA et al., 2005) and references herein. Boundary conditions are updated in the boundaries of the regional model every 12 hours.

The ECHAM5 model drives the E5A2 and E5B1 experiments. This consists of the atmospheric model ECHAM5 coupled to the Max Plank Institute Ocean Model (MPI/OM) (JungClaus et al., 2006). The atmospheric model is used with a resolution $\mathrm{T} 63\left(\sim 1.875^{\circ}\right.$ $\left.\times 1.875^{\circ}\right)$, while the ocean resolution is about $1.5^{\circ} \times$ $1.5^{\circ}$. Boundary conditions were updated every 6 hours.

\subsection{EOF analysis}

In order to investigate the warming signal along the XXI century an Empirical Orthogonal Function (EOF) analysis was used (LORENZ, 1956; VON STORCH and ZWIERS, 2007; HANNACHI et al., 2007). This methodology reduces the high dimensionality of complex phenomena by decomposing a space-time field into spatial patterns and associated time indices:

$$
T(t, \mathbf{s})=\sum_{i=1}^{N} \operatorname{PC}_{i}(t) \mathrm{EOF}_{i}(\mathbf{s}),
$$

where $N$ is the number of modes contained in the field, $\mathrm{EOF}_{i}(\mathbf{s})$ are a set of functions defined for space and $\mathrm{PC}_{i}(t)$ their temporal coefficients, usually called Principal Components. The difference between the original field and the first member of the summation is the residual,

$$
\begin{aligned}
\operatorname{Res}(t, \mathbf{s}) & =T(t, \mathbf{s})-\mathrm{PC}_{1}(t) \mathrm{EOF}_{1}(\mathbf{s}) \\
& =\sum_{i=2}^{N} \operatorname{PC}_{i}(t) \mathrm{EOF}_{i}(\mathbf{s})
\end{aligned}
$$

Therefore the analysis of the residual series has to be performed in order to evaluate whether the EOF analysis is able to filter out the warming signal trend.

To illustrate the methodology, the monthly series of daily maximum 2-m temperature for July in the EGA2 experiment (Table 1) is studied herein in detail. Similar results are produced for the rest of the months in every experiment. Figure 2 depicts the time evolution of the domain-averaged anomalies of maximum 2-m temperature for July, the corresponding $\mathrm{PC}_{1}$ and the residual. The correlation between the average 2-m temperature and the first PC is nearly one. The residual presents no trend and its variance is much smaller. The residual, which is dominated by $\mathrm{EOF}_{2}$ (not shown), has a bipolar structure, so the domain-averaged series is not sufficient to test the robustness of the methodology. For this reason, Figure 3 shows the complementary picture in the spatial domain for the same data set. The corresponding $\mathrm{EOF}_{1}$ is shown in the bottom-left panel of Figure 4. The original data set exhibits trends up to $1 \mathrm{~K} /$ decade in some central-west areas of the IP, decreasing in amplitude to the coast, while the residual trends are roughly one order of magnitude smaller. These two facts, plus 
Table 2: Percentage of the total variance explained by the first EOF of the associated series. Information is split into variables, model runs and months (by rows).

\begin{tabular}{c|cc|cc|cc|cc}
\hline & \multicolumn{2}{|c|}{ E5A2 } & \multicolumn{2}{c|}{ E5B1 } & \multicolumn{2}{c|}{ EGA2 } & \multicolumn{2}{c}{ EGB2 } \\
Month & $T \max$ & $T \min$ & $T \max$ & $T \min$ & $T \max$ & $T \min$ & $T \max$ & $T \min$ \\
\hline Jan & 84.96 & 84.88 & 83.43 & 83.26 & 87.10 & 85.85 & 80.13 & 76.13 \\
Feb & 84.31 & 83.85 & 81.76 & 80.60 & 85.69 & 87.90 & 83.07 & 82.51 \\
Mar & 84.41 & 85.71 & 76.18 & 77.95 & 84.36 & 86.05 & 82.40 & 81.67 \\
Apr & 82.01 & 81.97 & 75.40 & 73.29 & 86.69 & 86.60 & 82.60 & 82.33 \\
May & 81.58 & 79.03 & 71.45 & 71.03 & 87.09 & 85.08 & 81.28 & 79.17 \\
Jun & 81.12 & 79.84 & 70.60 & 73.26 & 89.69 & 88.88 & 78.17 & 76.64 \\
Jul & 81.88 & 81.89 & 73.51 & 75.79 & 89.63 & 90.04 & 80.67 & 82.10 \\
Aug & 83.41 & 84.88 & 74.21 & 79.08 & 88.32 & 89.77 & 78.22 & 81.67 \\
Sep & 84.98 & 86.16 & 78.10 & 82.99 & 85.82 & 89.13 & 79.66 & 82.92 \\
Oct & 84.18 & 84.00 & 72.86 & 77.55 & 88.68 & 89.69 & 81.40 & 84.01 \\
Nov & 89.16 & 88.05 & 79.17 & 80.74 & 87.21 & 85.72 & 84.79 & 84.95 \\
Dec & 86.03 & 84.95 & 84.46 & 84.79 & 86.98 & 84.89 & 83.40 & 82.67 \\
\hline
\end{tabular}

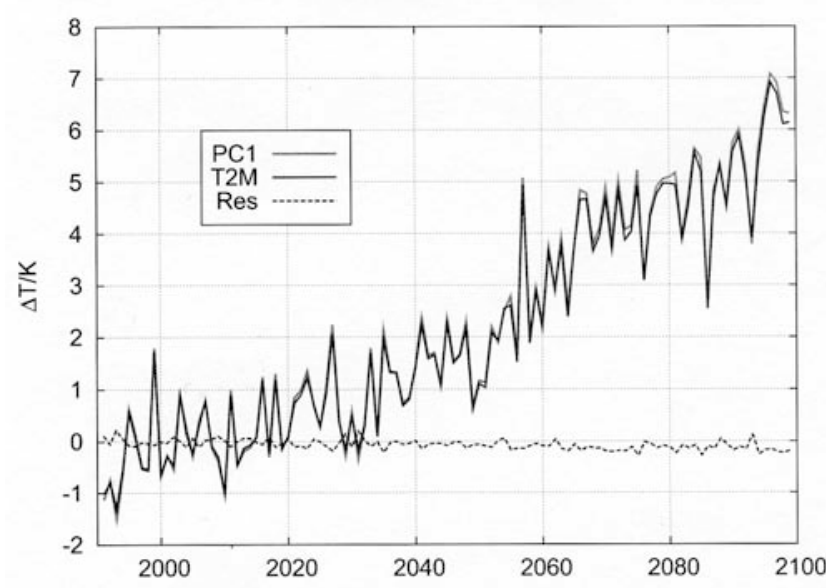

Figure 2: Anomalies in the spatial averaged maximum temperature versus $\mathrm{PC}_{1}$ and the residual. The series correspond to July monthly means for the EGA2 experiment.

the large amount of variance explained by $\mathrm{EOF}_{1}(89 \%$ of the total, Table 2), imply that this pattern contains the spatial structure of the warming pattern, as obtained by other authors for GCMs (ZORITA et al., 2005).

\section{Results}

The EOF methodology presented in the previous section was applied independently to the monthly mean series of daily maximum and minimum 2-m temperatures for the four experiments. Table 2 depicts the amount of total variance explained by just the first EOF in each scenario, variable, and month, which is greater than 70 $\%$ in all cases. Moreover the $\mathrm{EOF}_{1}$ is able to filter out the warming trend, and, for this reason, only the first EOF will be studied, below-referred to as the warming pattern.

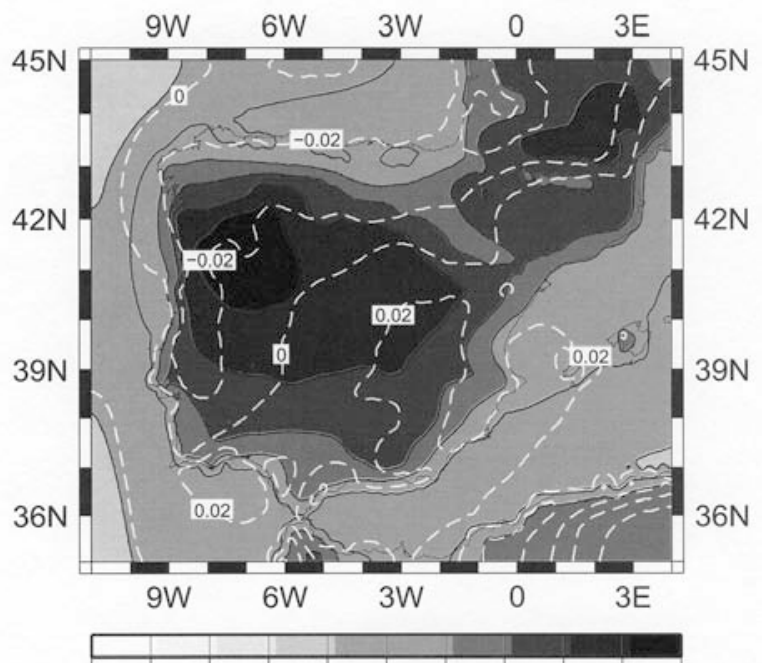

$\begin{array}{llllllllllll}0.0 & 0.1 & 0.2 & 0.3 & 0.4 & 0.5 & 0.6 & 0.7 & 0.8 & 0.9 & 1.0\end{array}$ trend $(\mathrm{K} / \mathrm{dec}$.)

Figure 3: Trends of the monthly mean series for July for the whole simulation period in the EGA2 experiment (grey shaded) and trends for the corresponding residual series (white contours). Both data sets are expressed in Kelvin per decade.

\subsection{Warming patterns}

Figure 4 (Figure 5) depicts the first EOF obtained for the E5A2 experiment for maximum (minimum) temperatures for January, April, July and October (one representative month per season). The rest of the months (not shown) present an intermediate behaviour. In general, warming patterns associated to maximum and minimum temperatures present some similarities, although there are important differences (discussed below).

In order to check whether the warming patterns depend on the SRES scenario, the spatial correlations between warming patterns in the E5A2 and E5B1 experiments for maximum and minimum temperatures in each month have been calculated (Table 3 first and second columns). In all cases the correlation is above 0.9. Sim- 

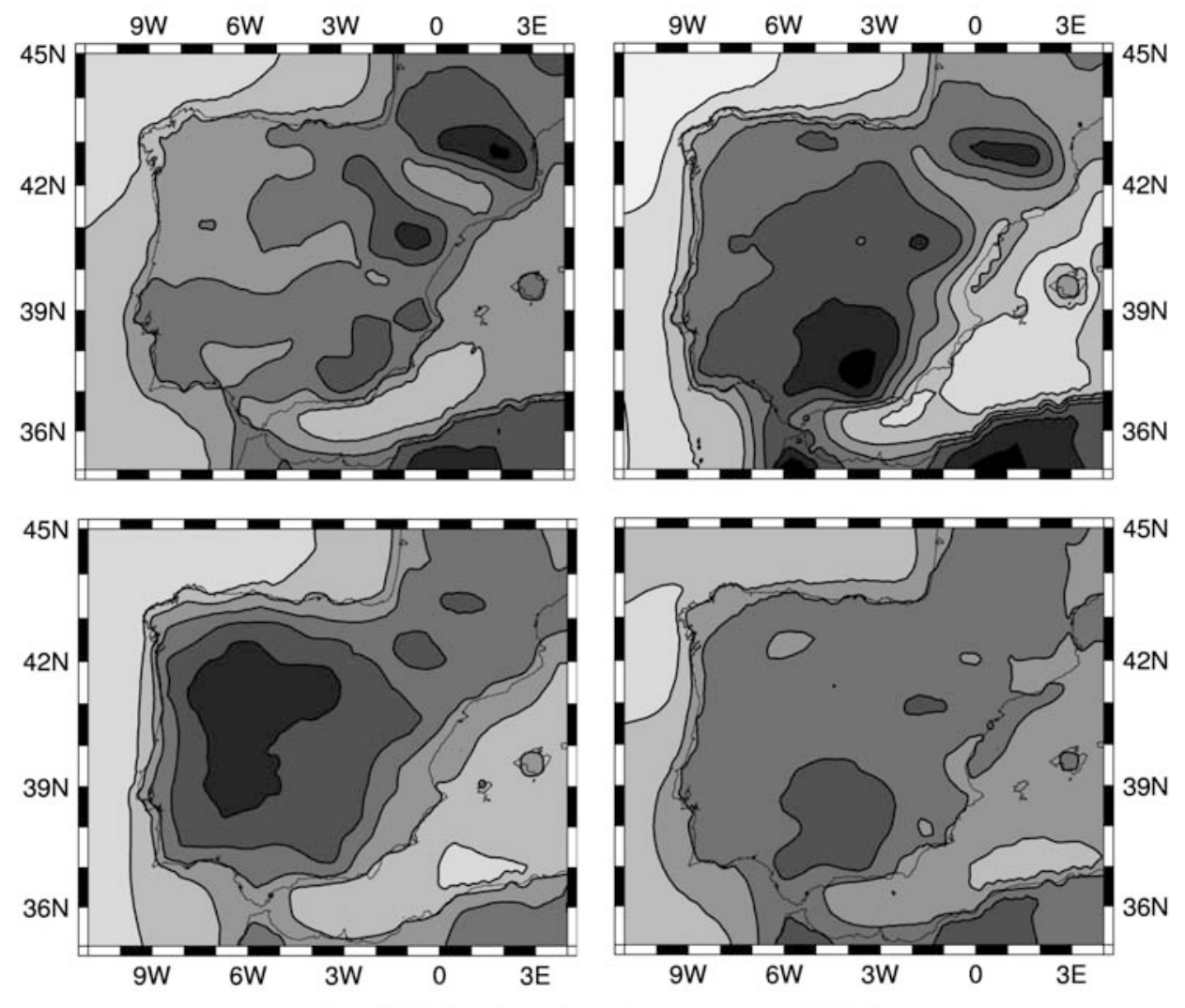

$\begin{array}{llllllllllll}0.0 & 0.2 & 0.4 & 0.6 & 0.8 & 1.0 & 1.2 & 1.4 & 1.6 & 1.8\end{array}$

Figure 4: First EOF obtained from maximum 2-m temperature monthly series for the E5A2 experiment. Only one representative month per season is presented: January (top left), April (top right), July (bottom left) and October (bottom right). Other months present an intermediate behaviour.

Table 3: Spatial correlation coefficient for each month between the warming patterns corresponding to different experiments. Only land points have been considered.

\begin{tabular}{c|cc|cc|cc}
\hline & \multicolumn{2}{|c|}{ E5A2 vs. E5B1 } & \multicolumn{2}{c|}{ EGA2 vS. EGB2 } & \multicolumn{2}{c}{ E5A2 vS. EGA2 } \\
Month & $T \max$ & $T \min$ & $T \max$ & $T \min$ & $T \max$ & $T \min$ \\
\hline Jan & 0.98 & 0.99 & 0.94 & 0.97 & 0.79 & 0.88 \\
Feb & 0.98 & 0.98 & 0.94 & 0.91 & 0.82 & 0.83 \\
Mar & 0.95 & 0.93 & 0.96 & 0.97 & 0.85 & 0.81 \\
Apr & 0.99 & 0.97 & 0.96 & 0.94 & 0.89 & 0.80 \\
May & 0.98 & 0.98 & 0.98 & 0.96 & 0.89 & 0.78 \\
Jun & 0.84 & 0.90 & 0.98 & 0.97 & 0.88 & 0.83 \\
Jul & 0.93 & 0.93 & 0.98 & 0.96 & 0.90 & 0.88 \\
Aug & 0.92 & 0.90 & 0.92 & 0.86 & 0.81 & 0.79 \\
Sep & 0.97 & 0.95 & 0.92 & 0.77 & 0.79 & 0.73 \\
Oct & 0.95 & 0.95 & 0.89 & 0.61 & 0.75 & 0.66 \\
Nov & 0.85 & 0.93 & 0.94 & 0.84 & 0.66 & 0.61 \\
Dec & 0.95 & 0.97 & 0.84 & 0.96 & 0.74 & 0.89 \\
\hline
\end{tabular}

ilarly, the correlations between EGA2 and EGB2 experiments are shown in the third and fourth columns for maximum and minimum warming patterns, respectively. Again, the spatial correlation is very high, albeit there are some months showing some differences (correlation in October for minimum temperatures is 0.61 ). Hence, the spatial warming patterns hardly change under different SRES scenarios, and thus, given the same GCM, the effect of changing GHG concentrations has to be sought in the intensity of the warming, rather than in the spatial structure of the warming patterns. Similar results have been found by NUNEZ et al. (2009) for southern South America using the future-minus-present method.

The question of whether the warming patterns depend on the GCM version driving the simulation may be explored through comparing the E5A2 and EGA2 simulations, corresponding to the same SRES scenario, A2. The correlations between warming patterns associated to these experiments are shown in Table 3 in columns 5 and 6. In this case, correlations are in general slightly lower than in former cases, reaching 0.61 in November for minimum temperatures. Nevertheless, the average correlation is still around 0.8 , and more than 0.85 for several months. The fact that correlation between different GCM versions is lower than between different SRES scenarios means than there is more resemblance between warming patterns associated to same GCM under different scenarios than to the same scenario with different GCM. It should be emphasised that the two 

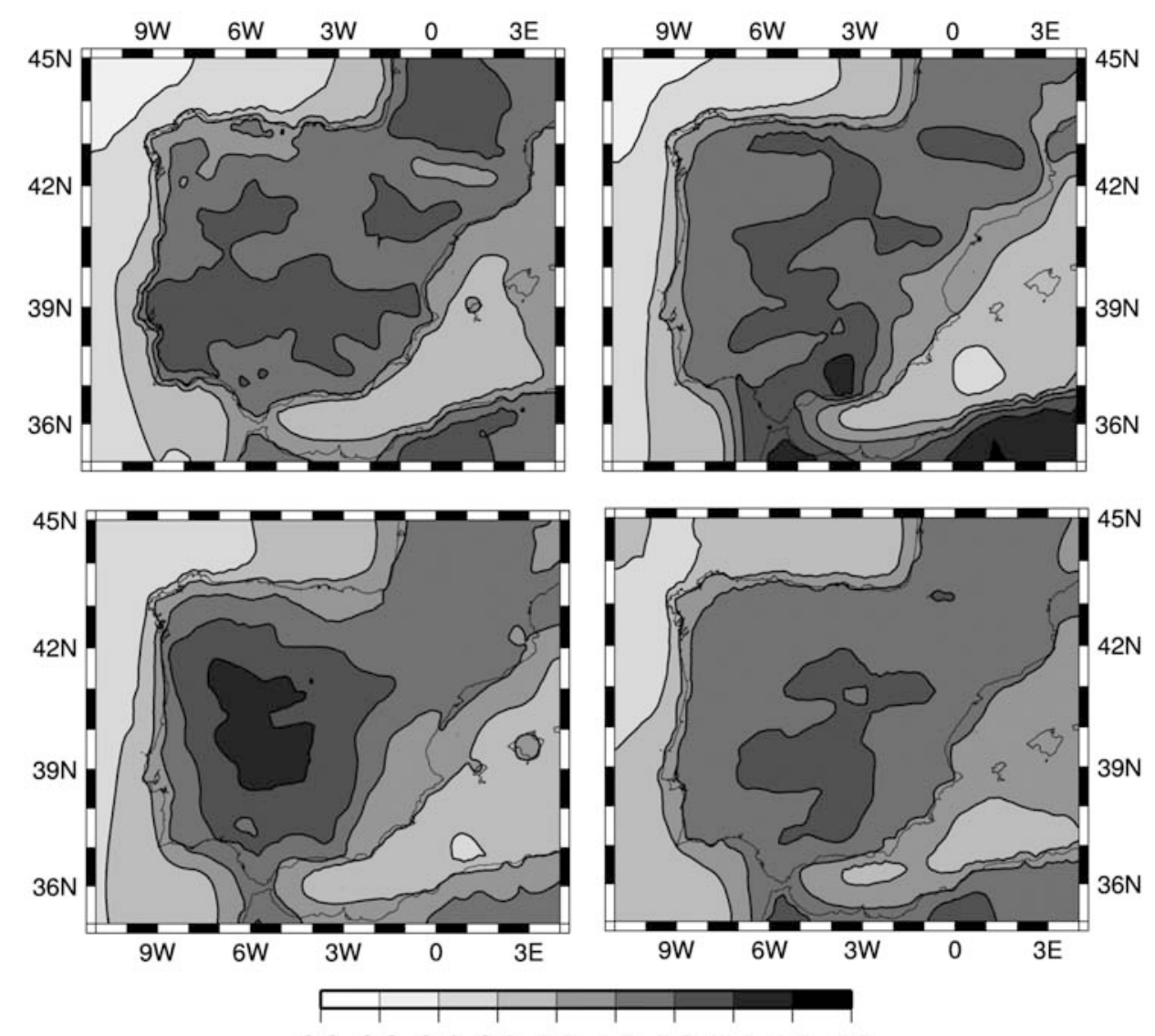

$\begin{array}{lllllllllll}0.0 & 0.2 & 0.4 & 0.6 & 0.8 & 1.0 & 1.2 & 1.4 & 1.6 & 1.8\end{array}$

Figure 5: First EOF obtained from minimum 2-m temperature monthly series for the E5A2 experiment. Only one representative month per season is presented: January (top left), April (top right), July (bottom left) and October (bottom right). Other months present an intermediate behaviour.

tested GCM were implemented with two versions of the same atmospheric model, ECHAM. This aspect will be discussed further in the final discussion.

The shapes of the warming patterns seem to be related with several geographical parameters, such as altitude and distance to the sea. Figures 4 and 5 indicate a pattern linked to the distance to the sea in the first EOF for July, meanwhile for April they seem to be related to orography. The annual cycle of these relationships is further explored in Figure 6. Figure 6a depicts the correlation between the warming pattern for each month for maximum and minimum temperature in the E5A2 experiment and distance to the sea, defined as the minimum distance from the grid point to the sea. In summertime the warming patterns are mostly related with the distance to the sea, with a correlation above 0.6 for maximum and minimum temperatures. This signal disappears and even becomes negative in wintertime for maximum temperatures, but remains significant for minimum temperatures in the first months of winter, clearly showing the discrepancies between the maximum and minimum temperatures mentioned above. On the other hand, Figure $6 \mathrm{~b}$ shows the correlation between patterns and altitude with respect to sea level. The relationship between them seems to be stronger in the principal mountain systems. For this reason, only grid points above 800 metres were taken into account in the calculations. This explicitly removes the IP Central Plateau, where the orographic signal is weaker. This figure shows a complementary behaviour with the former: warming patterns in the colder months are related to altitude, with correlations up to 0.5 for maximum ( 0.3 for minimum) temperatures in February, while in summer correlations are low or negative, giving way to the influence of the distance-to-sea pattern. Again the differences in the behaviour of the maximum and minimum patterns may be easily identified in this figure in January and December, where the correlations between maximum and minimum warming patterns and the orography are 0.3 and -0.2 , respectively.

Although there is no completely satisfactory explanation for the physical processes governing the shape of the warming patterns, the distance-to-sea pattern in the warmest months may be linked with the larger thermal capacity of oceans, which smoothes trends near coast lines. As regards the orography, it has been argued (GIORGI et al., 1997) that a positive feedback between melting snow cover on summits and albedo may be responsible for the increase of warming with altitude. 

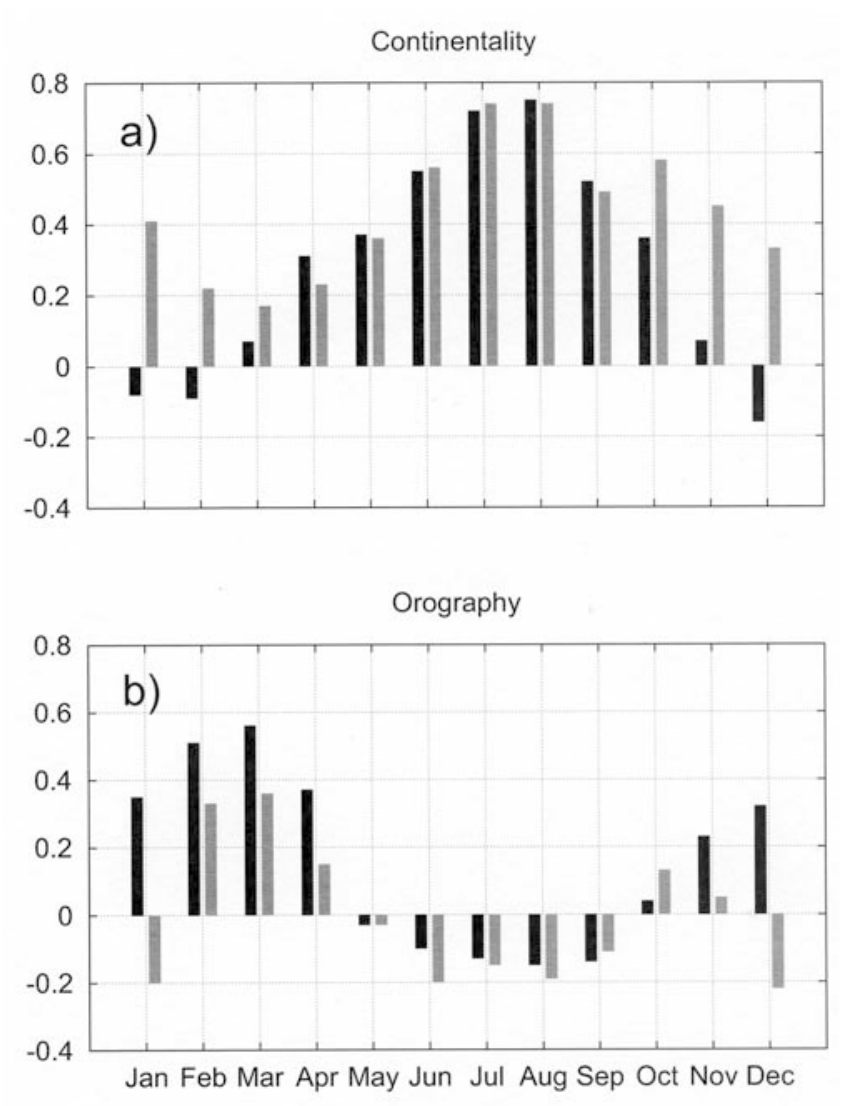

$T \max =T \min$

Figure 6: Annual cycle of correlation coefficients between maximum (black boxes) and minimum (grey boxes) warming patterns with: a) continentality, b) altitude referred to the sea level for the E5A2 experiment.

This possibility has been ruled out over the IP by using two different land soil models to perform the same simulation, one of which is capable to dynamically model the snow cover while the other uses prefixed values depending on the season. The resulting warming patterns in both experiments exhibit a similar correlation with altitude (GómEZ-NAVARRO et al., 2009). Further research should be devoted to identifying the reasons for increased warming with altitude, which may be related with changes in the large-scale circulation.

The asymmetry in the spatial structure of the warming patterns for maximum and minimum temperatures may have important implications for the projected evolution of the daily temperature range (DTR). In particular, zones where maximum temperatures rise more than minimum temperatures tend to develop a higher DTR.

\subsection{Temporal evolution}

As stated in the previous section, the scenarios and GCM versions driving the regional simulations tested in this work do not strongly modify the spatial structure of the warming, which seems to be an inherent feature of the regional model configuration and the chosen domains. The effect of these factors is to modify the amplitude of the warming trend. Figure 7 shows the first PCs of the monthly mean of daily maximum and minimum 2$m$ temperature series for the E5A2 and E5B1 experiments, while Figure 8 depicts the same results for EGA2 and EGB2. Generally, the stronger the GHG forcing, the larger the trend associated to maximum and minimum temperatures, as is to be expected. A difference up to 2 $\mathrm{K}$ in the maximum 2-m temperature series exists at the end of the XXI century for July when comparing E5A2 and E5B1 experiments, as shown in Figure 7. Similar results can be found for EGA2 and EGB2 experiments in Figure 8.

Nevertheless, this difference between scenarios depends strongly on the month, reaching just $1 \mathrm{~K}$ of difference in January for the ECHO-G-driven experiments, and showing negligible difference for those driven by ECHAM5. The internal variability plays an important role here. Although a 31 year running mean has been performed to the RCM data, the GCM has its own variability, which is passed to the RCM through the boundary conditions. This GCM natural variability explains why the model response in the E5B1 simulation for January is even greater than in the E5A2 until 2050 (top left panel in Figure 7). In general, given a GCM, the differences between scenarios follow an annual cycle (not shown), in which warmer months tend to be more sensitive to stronger GHG forcings. This suggests than the model projects not only warming, but also an increased difference between summer and winter.

Although the trends are positive in every case, except for April in the E5B1 experiment until 2040 (top right panel of Figure 7), which may be attributable to internal variability of the GCM, maximum temperatures, in general, show a more pronounced trend than the minima. This behaviour is more noticeable in warm months, as well as in the scenarios where GHG forcing is more intense, as can be appreciated in both figures. In the EGA2 experiment the difference between maximum and minimum PC anomalies at the end of the XXI century is around $1 \mathrm{~K}$ for July, while it is nearly $0 \mathrm{~K}$ for January. Similar results, although less intense, are found in the other experiments. These different trends imply a coherent increase in the DTR in this ensemble of regional projections for the XXI century, being more intense in the more pessimistic scenarios. This behaviour has been further explored by JEREZ et al. (2009), who pointed to a relationship between the intensification of the DTR and the projected decrease of available moisture over the IP.

The increased DTR, as well as the differences between summer and winter, would suggest a continentalization of the climate over the IP. It should be highlighted that the only effect of imposing different SRES scenarios and GCMs is to modify the intensity and the moment when these changes occur. That is, the continentalization of 

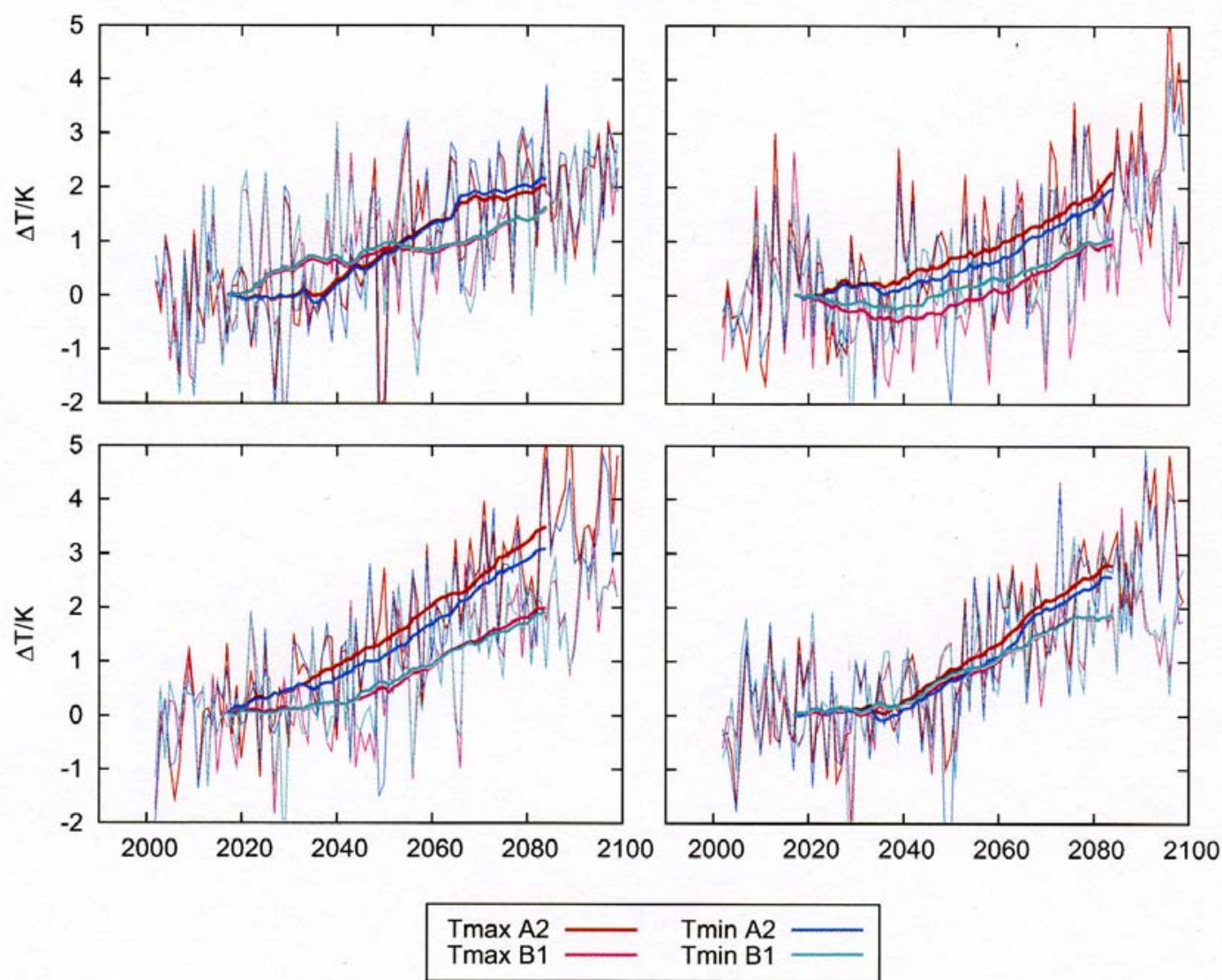

Figure 7: First PC anomalies, referred to its mean in the first 31 years, of maximum and minimum (red and blue lines, respectively) 2 $\mathrm{m}$ temperatures for E5A2 (dark colours) and E5B1 (light colours) experiments. Thick lines represent a 31-year running mean. Only one representative month per season is represented: January (top left), April (top right), July (bottom left) and October (bottom right).

the IP is a common feature of all the climate change projections discussed in this paper.

\section{Discussion}

The usual approach in this kind of study is to calculate the differences between averages of each variable for two periods of time, as reference (usually several years in the past) and for the future. Instead, this work focuses on an EOF analysis, which is able to account for the warming signal, the first EOF capturing the temperature trends along the simulated period. This methodology, not used so far in RCM studies, tries to overcome the problem linked to the internal variability of RCMs, as it employ the whole transient simulation to calculate the warming patterns.

The spatial structure of the warming patterns has a marked annual cycle. In addition, there is an important asymmetry between maximum and minimum $2-\mathrm{m}$ temperatures. Nevertheless, these patterns depend neither on the SRES scenario nor on the GCM version used to drive the regional simulations. They are, rather, an inherent feature of the considered domains. It is nevertheless important to note that these conclusions could be modified if different RCM configurations or a larger set of GCMs are employed. In particular, the two GCM employed were implemented with two versions of the atmospheric model ECHAM. Thus, although two different ocean models were used in the GCM setup, they are not completely independent. It would be interesting to check whether these patterns remain similar under other completely independent GCMs. Such an analysis will be performed in future studies.

The warming patterns seem to be associated to several geographical parameters such as distance to the sea or altitude. The positive feedback between the melting of snow cover on summits and albedo as being responsible for the relationship between orography and warming has been ruled out in previous communications (GóMEZNAVARRO et al., 2009). In addition, the distance-to-sea pattern may be related with the larger thermal capacity of oceans. Nevertheless, there is no completely satisfactory explanation of the physical mechanisms underlying this behaviour, and further research should be devoted to an attempt to fully understand. 

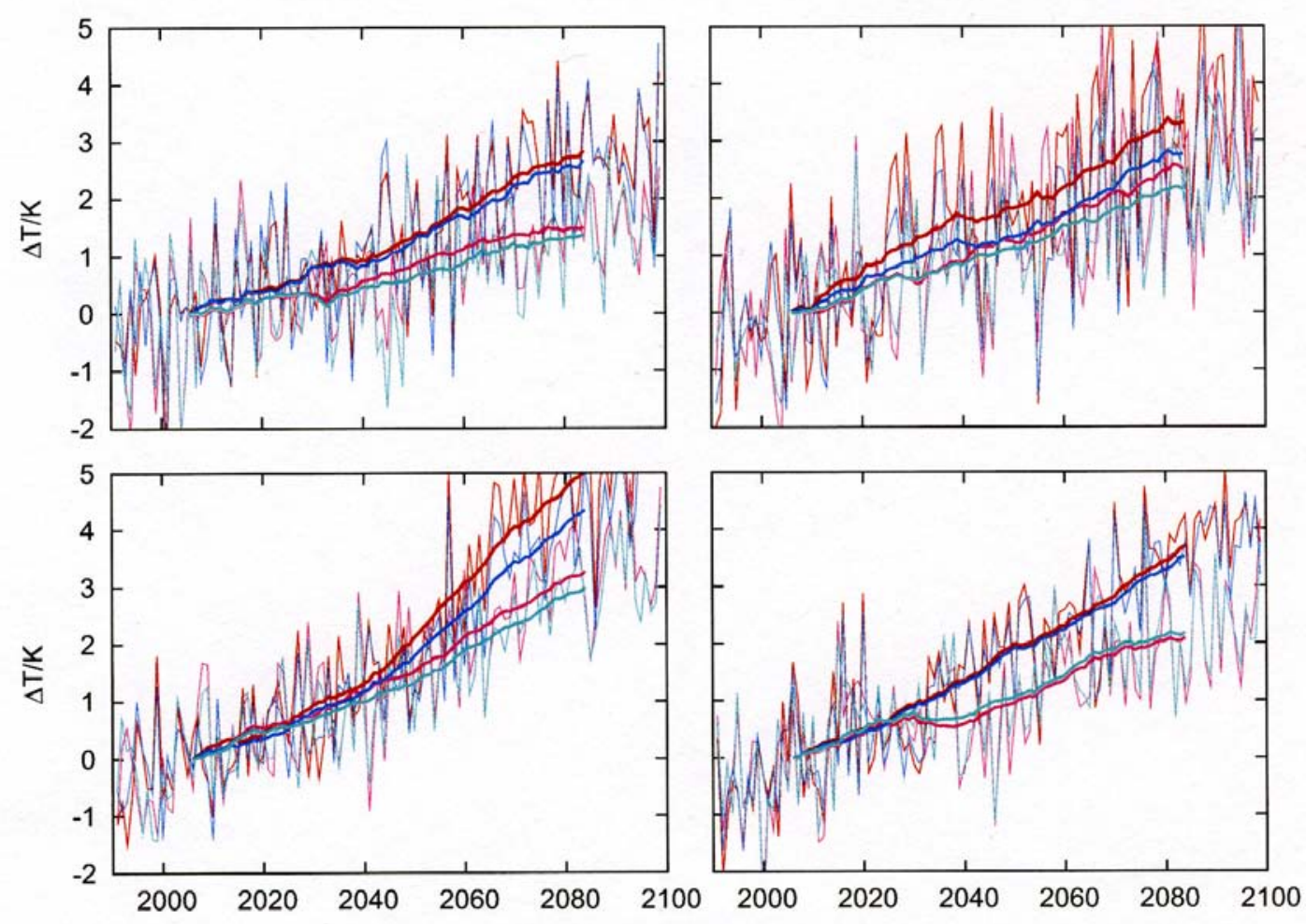

$\begin{array}{ll}T \operatorname{Tmax} A 2 & \operatorname{Tmin} \mathrm{A} 2 \\ \mathrm{Tmax} \mathrm{B} 2 & \mathrm{Tmin} \mathrm{B} 2\end{array}$

Figure 8: First PC anomalies, referred to its mean in the first 31 years, of maximum and minimum (red and blue lines, respectively) 2-m temperatures for EGA2 (dark colours) and EGB2 (light colours) experiments. Thick lines represent a 31-year running mean. Only one representative month per season is represented: January (top left), April (top right), July (bottom left) and October (bottom right).

Maximum temperature trends are more pronounced than minimum ones. These differences also depend on the month, being stronger in summer. This asymmetry yields a continentalization of the climate over the IP for the projected period. One important result is that these projections are consistent in all the scenarios studied. The effect of changing the forcing conditions (i.e. the GHG concentrations) is to modulate the global trends over the IP, not to modify the spatial structure of the projected warming or the continentalization of the climate.

Internal variability plays an important role in the simulations, adding an important uncertainty factor to the results. Trying to overcome this problem, long fulltransient simulations have been performed, and temporal series have been filtered out by means of a 31 year running mean. Nevertheless, the internal variability of the GCM is passed through the boundaries to the RCM, leading to some unexpected results, like the cooling trends seen in several months in the the E5B1 simulation. The internal variability problem can be faced by downscaling a larger set of GCM runs. For this reason, and due to the similarities between the two GCMs employed in this study, in future works a more complete set of simulations will be performed, using completely independent GCMs and different SRES scenarios in order to reinforce the present results.

It should be highlighted that the aforementioned results depend on the fact that the physics and the configuration of the domain are equal in all simulations. Further simulations should be performed modifying these factors. Such sensitivity studies would be helpful for assessing the uncertainties linked to the dynamic downscaling process itself. Analogously, different RCMs could be employed for checking differences and similarities between models. On the other hand, it would also be interesting to check whether the patterns found are present in the pre-industrial climate, as obtained by other authors in GCM experiments (ZORITA et al., 2005).

\section{Acknowledgements}

This work was funded by the Spanish Ministry of the Environment (project ESCENA, Ref. 20080050084265) and the Spanish Ministry of Science and Technology (project SPECMORE-CGL2008-06558-C02-02/CLI). The authors also gratefully acknowledge funding from 
the Euro-Mediterranean Institute of Water (IEA) and the Regional Agency for Science and Technology of Murcia (Fundación Séneca, Ref. 00619/PI/04 and 11047/EE1/09). J.J. GómeZ-NAVARRo thanks the Spanish Ministry of Education for his Doctoral scholarship (AP200604100). Thanks to the Max Planck Institute and DKRZ for providing the access and computational support necessary to get the GCM simulation data employed in this work. Also thanks to the professor Volker RATH for translating the abstract into German.

\section{References}

Boo, K.-O., W.-T. Kwon, H.-J. BAEK, 2004: Change of extreme events of temperature and precipitation over Korea using regional projection of future climate change. - Geophys. Res. Lett. 33, L01701.

Chen, F., J. Dudhia, 2001a: Coupling an Advanced Land Surface-Hydrology Model with the Penn State-NCAR MM5 Modeling System. Part I: Model Implementation and Sensitivity. - Mon. Wea. Rev. 129, 569-585.

_, _, 2001b: Coupling an Advanced Land SurfaceHydrology Model with the Penn State-NCAR MM5 Modeling System. Part II: Preliminary Model Validation. Mon. Wea. Rev. 129, 587-604.

Déque, M., R. Jones, M. Wild, F. Giorgi, J. ChrisTENSEN, D. HASSEll, P. Vidale, B. Rockel, D. JACob, E. KJellstrom, de M. CAstro, F. Kucharski, VAN DEN B. HURK, 2005: Global high resolution versus Limited Area Model climate change projections over Europe: quantifying confidence level from PRUDENCE results. - Climate Dynam. 25, 653-670.

Déque, M., D.P. Rowell, D. Luethi, F. Giorgi, J.H. Christensen, B. RoCKEL, D. JACOB, E. KJEllstrom, M. DE CASTRO, B. VAN DEN HURK, 2007: An intercomparison of regional climate simulations for Europe: assessing uncertainties in model projections. - Climatic Change 81(Suppl. 1), 53-70.

Diffenbaugh, N.S., J.S. PAL, F. Giorgi, X. GaO, 2007: Heat stress intensification in the Mediterranean climate change hotspot. - Geophys. Res. Lett. 34, L1706, DOI:10.1029/2007GL030000.

DuDHIA, J., 1989: Numerical study of convection observed during the winter monsoon experiment using a mesoscale two-dimensional model. - J. Atmos. Sci. 46, 3077-3107.

DudhiA, J., 1993: A nonhydrostatic version of the Penn StateNCAR mesoscale model: Validation tests and simulation of an Atlantic cyclone and cold front. - Mon. Wea. Rev. 121, 1493-1513.

Fernandez, J., J.P. Montavez, J. SAenz, J. F. GonZalez-Rouco, E. Zorita, 2007: Sensitivity of the MM5 mesoscale model to physical parameterizations for regional climate studies: Annual cycle. - J. Geophys. Res. Atmos. 112, D04101.

Font-Tullot, I., 2000: Climatología de España y Portugal - Ediciones Universidad de Salamanca, Salamanca.

Giorgi, F., 2005: Climate change prediction. - Climate Change 73, 239-265.

Giorgi, F., 2006: Climate change hot-spots. - Geophys. Res. Lett. 33, 11217-11222.

Giorgi, F., J.W. Hurrel, M.R. MArinuCCI, 1997: Elevation dependency of the surface climate change signal: A model study. - J. Climate 10, 288-296.
Giorgi, F., X. Bi, J. PAL, 2004a: Mean, interannual variability and trends in a regional climate change experiment over Europe. I. Present-day climate (1961-1990). - Climate Dynam. 22, 733-756.

Giorgi, F., X. Bi, J. PAL, 2004b: Mean, interannual variability and trends in a regional climate change experiment over Europe. II: climate change scenarios (2071-2100). Climate Dynam. 23, 839-858.

Gómez-Navarro, J.J., J. Montávez, S. Jerez, J. GARCÍA-VALERO, 2009: On the relationship between warming and orography in regional climate change projections (in Spanish). - In: Clima en España: Pasado. Presente y futuro. Contribución a un informe de Evaluación del Cambio Climático Regional: Resúmenes del congreso, 132, Madrid.

Grell, G. A., 1993: Prognostic evaluation of assumptions used by cumulus parameterizations. - Mon. Wea. Rev. 121, 764-787.

Grell, G.A., J. Dudhia, D.R. Stauffer, 1994: A description of the fifth-generation penn state/ncar mesoscale model (mm5). - Technical Report NCAR/TN-398+STR, National Center for Atmospheric Research.

HannaChi, A., I.T. Jolliffe, D.B. Stephenson, 2007: Empirical orthogonal functions and related techniques in atmospheric science: A review. - Int. J. Climatol. 27, 1119-1152.

Hawkins, E., R. Sutton, 2009: The potential to narrow uncertainty in regional climate predictions. - Bull. Amer. Meteor. Soc. 90, 1095-1107.

Hong, S.Y., H.L. PAN, 1996: Nonlocal boundary layer vertical diffusion in a medium-range forecast model. Mon. Wea. Rev. 124, 2322-2339.

Houghton, J.T., Y. Ding, D.J. Griggs, M. Noguer, VAN DER P.J. Linden, X. DAI, K. MASKELl, C.A. JoHnson, editors, 2001: Climate Change 2001: The Scientific Basis. Contribution of Working Group I to the Third Assessment Report of the Intergovernmental Panel on Climate Change. - Cambridge University Press, New York, 881.

IPCC, 2007: Climate Change 2007: The Physical Science Basis: Contribution of Working Group I to the Fourth Assessment Report of the Intergovernmental Panel on Climate Change. - Cambridge University Press, New York.

JaCob, D., L. Barring, O.B. Christensen, J. H. Christensen, De M. Castro, M. Déque, F. Giorgi, S. Hagemann, G. LENDERINK, B. Rockel, E. SANCHEZ, C. Schaer, S. I. SEnEviratne, S. Somot, A. van Ulden, B. VAN DEN HURK, 2007: An inter-comparison of regional climate models for Europe: model performance in present-day climate. Climatic Change 81(Suppl. 1), 31-52.

Jerez, S., J.P. Montávez, P. Jimenez-Guerrero, J.J. GómeZ-NAVArRo, J.F. GonZÁlez-Rouco, 2009: Influence of soil moisture-near surface temperature feedback on present and future climate simulations over the Iberian Peninsula. - In: 21st Century Challenges in Regional-scale Climate Modelling, number 41, 261-262, Lund University.

JungClaus, J.H., N. KeEnlyside, M. BotZet, H. HAAK, J.J. LUO, M. LATIF, J. MAROTZKe, U. Mikolajewicz, E. Roeckner, 2006: Ocean circulation and tropical variability in the coupled model ECHAM5/MPI-OM. - J. Climate 19, 3952-3972.

KitTel, T., F. Giorgi, G. MEeHL, 1998: Intercomparison of regional biases and doubled $\mathrm{CO}_{2}$-sensitivity of coupled atmosphere-ocean general circulation model experiments. 
- Climate Dynam. 14, 1-15.

LegutKe, S., R. Voss, 1999: The Hamburg atmosphereocean coupled circulation model ECHO-G. - Technical report, DKRZ.

Liang, X.-Z., K.E. Kunkel, G.A. Meehl, R.G. JONES, J.X.L. WANG, 2008: Regional climate models downscaling analysis of general circulation models present climate biases propagation into future change projections. - Geophys. Res. Lett. 35, L08709, DOI:10.1029/2007GL032849.

LorenZ, E. N., 1956: Empirical Orthogonal Functions and Statistical Weather Prediction. - Technical report, Massachusetts Institute of Technology.

Mlawer, E.J., S.J. Taubman, P.D. Brown, M. J. IACONO, S.A. ClOUGH, 1997: Radiative transfer for inhomogeneous atmospheres: Rrtm, a validated correlatedmodel for the longwave. - J. Geophys. Res. 102, 1666316682.

Montávez, J. P., J. Fernández, J. F. GonzálezRouco, J. SAEnZ, E. Zorita, F. VAlero, 2006: Climate change projections over the Iberian Peninsula (in Spanish). - In: V Asamblea Hispano Portuguesa de geodesia y geofísica, Sevilla.

Montávez, J.P., S. Jerez, J.J. Gómez-Navarro, J.F. GONZÁLEZ-ROUCO, 2008: Evaluation of soil models coupled to a RCM in simulating the Iberian Peninsula Climate. - In: Eos Trans. AGU. Fall Meet. Suppl., volume 89, GC53A-0706.

Nunez, M.N., S.A. Solman, M. Fernanda Cabre, 2009: Regional climate change experiments over southern South America. II: Climate change scenarios in the late twenty-first century. - Climate Dynam. 32, 1081-1095.

RAISANEN, J., 2001: CO2-induced climate change in CMIP2 experiments: Quantification of agreement and role of internal variability. - Journal of Climate 14(9), 2088-2104.
RAisANEN, J., U. HANSSON, A. Ullerstig, R. Doscher, L. Graham, C. Jones, H. Meier, P. SAMuelsson, U. Willen, 2004: European climate in the late twenty-first century: regional simulations with two driving global models and two forcing scenarios. Climate Dynam. 22, 13-31.

Rind, D., R. Goldberg, J. Hansen, C. Rosenzweig, R. RUEDY, 1990: Potential evapotranspiration and the likelihood of future drought. - J. Geophys. Res. Atmos. 95, 9983-10004.

Solman, S.A., M.N. Nunez, M.F. CABre, 2008: Regional climate change experiments over southern South America. I: present climate. - Climate Dynam. 30, 533552.

Trigo, R., J. Palutikof, 2001: Precipitation scenarios over Iberia: A comparison between direct GCM output and different downscaling techniques. - J. Climate 14, 44224446.

VON STORCH, H., 1995: Inconsistencies at the interface of climate impact studies and global climate research. Meteorol. Z. 4, 72-80.

VON Storch, H., F. ZWIERS, 2007: Statistical Analysis in Climate Research - Cambridge University Press.

Wilby, R., T. Wigley, D. Conway, P. Jones, B. HewitSON, J. MAIN, D. WILKS, 1998: Statistical downscaling of general circulation model output: A comparison of methods. - Water Resour. Res. 34, 2995-3008.

Xoplaki, E., J. Gonzalez-Rouco, J. Luterbacher, H. WANNER, 2004: Wet season Mediterranean precipitation variability: influence of large-scale dynamics and trends. - Climate Dynam. 23, 63-78.

Zorita, E., J. GONZALEZ-Rouco, H. vON StorCh, J. Montavez, F. VAlero, 2005: Natural and anthropogenic modes of surface temperature variations in the last thousand years. - Geophys. Res. Lett. 32, L08707, Doi:10.1029/2004GL021563. 